\title{
On-site or off-site treatment of medical waste: a challenge
}

\author{
Hassan Taghipour ${ }^{1 *}$, Taher Mohammadyarei ${ }^{2}$, Mohamad Asghari Jafarabadi ${ }^{3}$ and Ahmad Asl Hashemi ${ }^{1}$
}

\begin{abstract}
Treating hazardous-infectious medical waste can be carried out on-site or off-site of health-care establishments. Nevertheless, the selection between on-site and off-site locations for treating medical waste sometimes is a controversial subject. Currently in Iran, due to policies of Health Ministry, the hospitals have selected on-site-treating method as the preferred treatment. The objectives of this study were to assess the current condition of on-site medical waste treatment facilities, compare on-site medical waste treatment facilities with off-site systems and find the best location of medical waste treatment. To assess the current on-site facilities, four provinces (and 40 active hospitals) were selected to participate in the survey. For comparison of on-site and off-site facilities (due to non availability of an installed off-site facility) Analytical Hierarchy Process (AHP) was employed. The result indicated that most on-site medical waste treating systems have problems in financing, planning, determining capacity of installations, operation and maintenance. AHP synthesis (with inconsistency ratio of $0.01<0.1$ ) revealed that, in total, the off-site treatment of medical waste was in much higher priority than the on-site treatment (64.1\% versus 35.9\%). According to the results of study it was concluded that the off-site central treatment can be considered as an alternative. An amendment could be made to Iran's current medical waste regulations to have infectious-hazardous waste sent to a central off-site installation for treatment. To begin and test this plan and also receive the official approval, a central off-site can be put into practice, at least as a pilot in one province. Next, if it was practically successful, it could be expanded to other provinces and cities.
\end{abstract}

Keywords: Medical waste, Treatment, AHP, On-site, Off-site, A challenge

\section{Introduction}

Medical waste includes all of waste that is produced in the course of health protection, immunization, diagnosis, medical treatment of human beings or animals, scientific research and related laboratories [1-6]. Between $75 \%$ and $90 \%$ of the waste produced by healthcare providers is non-risk or general health-care waste, the remaining $10-25 \%$ of health-care waste is regarded as hazardous-infectious and may create a variety of health risks [2,7]. In the USA, about $15 \%$ of total hospital waste is considered as infectious waste. But in India this could range from $15 \%$ to $35 \%$ and in Iran about $29.89 \%$ depending on the total amount of waste produced $[8,9]$. The rate of generation of waste in Iran

\footnotetext{
* Correspondence: hteir@yahoo.com

${ }^{1}$ Department of Environmental Health Engineering, Tabriz University of Medical Sciences, Tabriz, Iran

Full list of author information is available at the end of the article
}

was reported 2.71-4.45 Kg/bed-day but in other countries that varies from $0.84-7 \mathrm{Kg} /$ bed-day $[2,8,10-15]$.

Basic principles of medical waste management include preventing and/or minimizing waste production, appropriately segregating general medical waste from hazardous-infectious medical waste, sending general medical waste to the municipal waste stream for final disposal and treating hazardous-infectious medical waste carefully using special methods [2,8,16-18]. For preventing and/or minimizing medical waste, implementation of certain policies and practices including the following ones can significantly help: choosing supplies and goods that are less wasteful or less dangerous, using physical rather than chemical cleaning methods, centralized purchasing of hazardous chemicals, monitoring chemical flows, ordering relatively small quantities rather than large amounts at one time, using the oldest batch of a product first, checking the expiry date of all products at the time of delivery, properly segregating general waste and hazardous-
C Biomed Central

(c) 2014 Taghipour et al.; licensee BioMed Central Ltd. This is an Open Access article distributed under the terms of the Creative Commons Attribution License (http://creativecommons.org/licenses/by/2.0), which permits unrestricted use, distribution, and reproduction in any medium, provided the original work is properly credited. 
infectious waste $[2,8]$. But, the most important step in waste minimization of medical waste is appropriate segregation of hazardous-infectious waste from general waste. The segregation process should be carried out by waste producers. Segregating and sending the general medical waste to municipal waste disposal system can reduce at least about $70 \%$ of quantity of total generated waste and, as a consequence, its related difficulties and problems. One of the practical ways for segregation is colour-coded method. However, the hazardous-infectious medical waste needs special attention for treatment and final disposal $[2-4,9,19,20]$. Treating the hazardous-infectious medical waste can be carried out on-site or off-site of health-care facilities $[2,8]$. A lot of studies have been carried out in different countries and also Iran about characterization, regulation, management and treatment of medical waste $[4,5,7,8,11,14,15,21-25]$. Also some of studies have been carried out in comparison of on-site and offsite (central) facilities and determining their advantages and disadvantages for medical waste treatment [17,26-28]. Nevertheless, the selection between on-site and off-site methods for treatment location of medical waste is a controversial subject especially in Iran.

Currently in Iran, due to policies of Health Ministry, the hospitals (and other major producers of medical waste) have selected on-site treating method as the preferred treatment. Because, according to Act 64 in Iran's Medical Waste Management Regulations, all waste producers in middle-sized and large cites are responsible for treating hazardous-infectious waste and converting it into general waste in on-site facilities. Only after on-site pre-treatment of medical waste will the municipality takes the responsibility for off-site transport of waste to the final disposal site. Nevertheless, according to the same Act of the regulation, small cities and villages are allowed to use off-site (central) facilities for treating their hazardous-infectious waste [29]. Based on Act 65 of Medical Waste Management Regulations in Iran, minor medical waste producers (physician's office, dental clinics, acupuncturists, chiropractors, small clinics, diagnostic laboratories) can use off-site (central or regional) facilities for treating their hazardous-infectious medical waste [29]. Another option for the minor medical waste producers is to send their waste to on-site establishment of neighboring hospitals [29].

In the meantime, there are great concerns about operation and maintenance conditions of on-site medical waste treatment facilities in hospitals. Therefore, the primary objective of this study was to assess the current condition of on-site medical waste treatment facilities in the country, compare on-site medical waste treatment facilities with off-site systems and find the best location by employing Analytical Hierarchy Process (AHP). In addition, this study aimed to make some practical recommendations on medical waste treatment for improving the current situation.

\section{Methodology}

In the beginning of the study for assessing current on-site medical waste treatment facilities, 4 out of 31 provinces in Iran including East Azerbaijan, Tehran, Isfahan and Gilan were selected to participate in the survey. The selection of provinces was done in such a way to cover virtually different geographies, climates, economies, cultures. Then, 10 active hospitals with on-site medical waste treatment facilities were selected in each province (totally 40 hospitals) for assessing their current conditions. The selection of hospitals was carried out in such a way to cover various categories of hospitals (i.e., governmental, educational, university, private, NGO and military) and sizes. Site visits (observational method) with completing checklist were conducted in all selected hospitals to gather the basic information and assess current working conditions of onsite medical waste treatment facilities. Then, to compare on-site and off-site medical waste treatment facilities, based on the experts' perspective Analytical Hierarchy Process (AHP) was employed. Different decision-making tools have been developed for application in the environmental field such as the Matrix Method, the AHP and the Electre III method. AHP is one of the most practical multiple choice decision making techniques among the available methods widely used [24,28]. It should be explained, currently there is not any installed off-site medical waste treatment facilities in country. So the direct comparison of two systems was not possible during this study.

\section{Criterion variables}

Twenty two criterion variables for on-site treatment and off-site treatment were chosen for the Analytical Hierarchy Process. Then, by brainstorming high-level experienced experts (and also considering previous experiences, literature review) thirteen final criterion variables (among twenty two primary criterion) for both on-site and off-site treatment was selected for calculation of treatment location (as listed in Table 1). The high-level experienced experts include academic staffs of environmental health engineering departments who have experience and research in medical waste and also the managers, technical staffs and experts of hospitals that have duty in medical waste treatment and disposal. A survey was carried out to validate the selection criteria. The survey results were incorporated in finalization of the list of criterion variables [17].

\section{Analytical Hierarchy Process}

All the analysis was performed using Expert Choice 11 software (Expert Choice Inc., Arlington, Virginia, USA). The input data for the analysis was the weighted means resulted from the primary evaluation of the panel 


\begin{tabular}{|c|c|c|}
\hline No & Criterion variables & Abbreviation \\
\hline 1 & Capital, maintenance and operation costs & (CMOC) \\
\hline 2 & Transportation cost of waste & $(\mathrm{TCW})$ \\
\hline 3 & $\begin{array}{l}\text { Costs and problems of air and wastewater } \\
\text { treatment }\end{array}$ & (CPAW) \\
\hline 4 & Energy requirements & (ER) \\
\hline 5 & Reliability and ease of operation & (REO) \\
\hline 6 & $\begin{array}{l}\text { Feasibility of treating medical waste of minor } \\
\text { medical producers }\end{array}$ & (FTMMP) \\
\hline 7 & $\begin{array}{l}\text { Feasibility of treating medical waste of the } \\
\text { surrounding area (cities and villages) }\end{array}$ & (FTMSA) \\
\hline 8 & Need for skilled operators & (NSO) \\
\hline 9 & Required space & (RS) \\
\hline 10 & $\begin{array}{l}\text { Continuous performance and monitoring } \\
\text { the system }\end{array}$ & (CPMS) \\
\hline 11 & Occupational risks in treatment site & (ORTS) \\
\hline 12 & $\begin{array}{l}\text { Environmental and health risks posed by } \\
\text { transportation }\end{array}$ & (EHRT) \\
\hline 13 & Compliance with laws and regulations & $(C L R)$ \\
\hline
\end{tabular}

experts, which was calculated in Microsoft Excel 2007 software. Analytical Hierarchy Process (AHP) technique was used in two steps to prioritize the objects; it prioritized the criteria in the first step and alternative locations in the second step. In the AHP procedure, as one of multiple decision-making techniques, Eigen values and eigenvectors were computed based on the input data matrix; afterwards, the priority weights were computed to rank the criteria and alternatives. In this procedure, the inconsistency ratio was calculated to investigate consistency of ranking made by the experts. This index ranged between zero (complete consistency) and one (complete inconsistency) and the values lower than 0.1 indicated a reasonable level of ranking consistency and hence confirmed the results of prioritizing the objects. The results of the analysis were presented based on absolute and normalized weights; the absolute weights ranging between 0 and 1 with higher weights showed the higher rank and higher priority of the objects. To normalize the weights, the maximum weight would be transferred to one and other weights would change correspondingly.

\section{Results and discussion}

\section{Current condition of medical waste treatment in on-site installations}

One of the first and most important steps in making an effective decision for selection of location treatment site is to assess current experiences. Due to not using off-site medical waste treatment system in Iran, only on-site system was assessed for determining the current condition.
The survey on the kind of treatment technologies which have been employed in the on-site installations of the studied hospitals indicated that most of used methods included autoclave, hydroclave, chemical treatment and incinerator successively. The result of site visiting, completing checklist and gathering the related data for operating and maintaining on-site medical waste treatment systems are presented in Table 2 . As indicated that table, capital cost of the used land and treating equipment was considerable in each hospital (about 85500 \$). By applying the operation and maintenance cost in a long term, that will be even more noticeable. Selecting and ordering treating equipment is generally carried out without primary study of the amount of generated medical waste in each hospital and also considering the capacity of chosen devices. Most of the hospitals (82.5\%) were equipped only with one treatment equipment, if the system found any technical problem, all the hazardous-infectious would be sent out without any treatment. In other $17.5 \%$ of hospitals which had parallel treating devices, the extra treating capacity was almost zero. Each on-site treatment facility needed at least two fulltime highly skilled technicians only for operating treating equipment. Nevertheless, allocation of two highly skilled technicians with current financial problems of hospitals almost was not practical. On the other hand, not allocation of proficient operators itself could cause the increase of operation and maintenance costs in the long run. According to the result of this study in 40 on-site medical waste treatment facilities in 4 provinces of Iran, about $32.5 \%$ of hospitals had difficulties in preparing spare parts of systems. It should be explained that most of on-site medical waste treatment facilities were recently installed. Probably, over time and by aging of facilities and treating systems, those operating and maintaining problems would be more noticeable in future. Almost none of 40 studied hospitals (with on-site treatment facilities) accepted and treated hazardous-infectious waste of minor medical waste producers of the city or the medical waste generated in the surrounding small cities and villages. Therefore, in the current condition, almost all minor medical waste producers sent their hazardous-infectious waste along with municipal waste stream without any treatment for final disposal. Because as indicated in Table 2, the major medical waste generators themselves had many problems with their on-site medical waste treatment systems due to high capital cost and also operation and maintenance problems and costs.

\section{Comparing on-site and off-site treatment of medical waste by Analytical Hierarchy Process (AHP)}

AHP presented results in several steps. First, prioritizing the criterion variables in which capital, maintenance and 
Table 2 Summary of assessing current on-site medical waste treatment systems in the studied area (40 hospitals)

\begin{tabular}{|c|c|c|c|}
\hline No & Surveyed subject & Result in the st & udied hospitals \\
\hline 1 & Average used land $\left(\mathrm{m}^{2}\right)$ in each hospital & About $86.25 \mathrm{~m}^{2}$ & \\
\hline 2 & Average cost per square meter (US \$) & About $585 \$$ & \\
\hline 3 & Average capital cost of land per on-site facilities (US \$) & About $50500 \$$ & \\
\hline 4 & Average capital cost per treating equipment (US \$) & About $35000 \$$ & \\
\hline 5 & Using special foundation for installing treating equipment & Yes (55\%) & No $(45 \%)$ \\
\hline 6 & Selected treating equipment from internal producers or from abroad & Internal (67.5\%) & Abroad (33.5\%), \\
\hline 7 & Reporting any problem regarding availability of spare parts and maintenance of system & Yes $(32.5 \%)$ & No $(67.5 \%)$ \\
\hline 8 & Average working hours per day & About $6 \mathrm{~h}$ & \\
\hline 9 & Required skilled operators & At least 2 & \\
\hline 10 & Allocation of highly skilled operators for treating equipment & Yes $(0 \%)$ & No $(100 \%)$ \\
\hline 11 & Selecting treating equipment capacity according to previous determination of the amount of medical waste & Yes $(0 \%)$ & No $(100 \%)$ \\
\hline 12 & Having parallel treating equipment for emergency conditions (phasing out of the system) & Yes (17.5\%) & No $(82.5 \%)$ \\
\hline 13 & Reliability of treating equipment according to self statement of operators & Yes (72.5\%) & No $(27.5 \%)$ \\
\hline 14 & Using air pollution control system for treating equipment (incinerators) & No $(100 \%)$ & \\
\hline 15 & Accepting and treating medical waste of minor medical producers in the city & Yes $(0 \%)$ & No $(100 \%)$ \\
\hline 16 & Accepting and treating medical waste of the surrounding cities and villages & Yes (0\%) & No $(100 \%)$ \\
\hline 17 & Management quality of on-site facilities space from health viewpoint & Good (62.5\%) & $\operatorname{Bad}(37.5 \%)$ \\
\hline
\end{tabular}

operation costs $(\mathrm{CMOC}=0.093)$, continuous performance and monitoring the system $(\mathrm{CPMS}=0.078)$ and occupational risks in treatment site (ORTS $=0.078)$ were prioritized as three first variables with the highest level of importance and need for skilled operators $(\mathrm{NSO}=0.073$ ) required space $(R S=0.073)$ and transportation cost of waste $(\mathrm{TCW}=0.071)$ as three variables with lower level of importance (Figure 1). In this step, the inconsistency ratio (ICR) was 0.00612 with zero missing judgment, which confirmed the consistency of ranks suggested by experts.
In the next step, for each criterion, on-site versus off-site treatment of medical waste was compared and prioritized. In each case, the ICR $<0.1$ showed acceptable level of ranking consistency. Also in this step, the results showed that, for CMOC, CPAW, ER, FTMMP, FTMSA, NSO, RS and CPMS criterion variables, off-site treatment was at higher level of priority (Figure 2). But, for transportation cost of waste (TCW) and environmental and health risks posed by the transportation (EHRT) criteria, on-site treatment had higher importance. Also for CLR criterion,

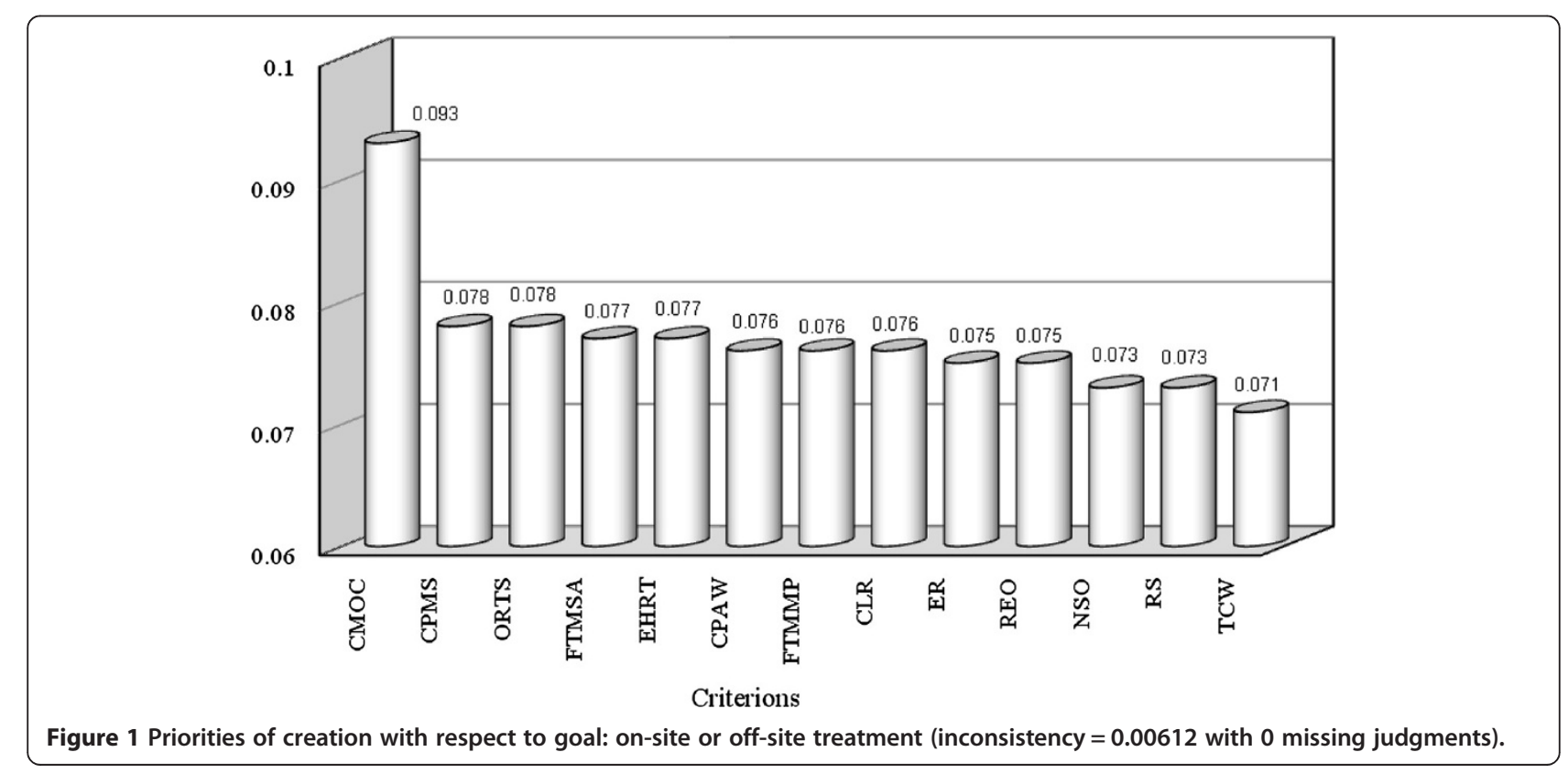




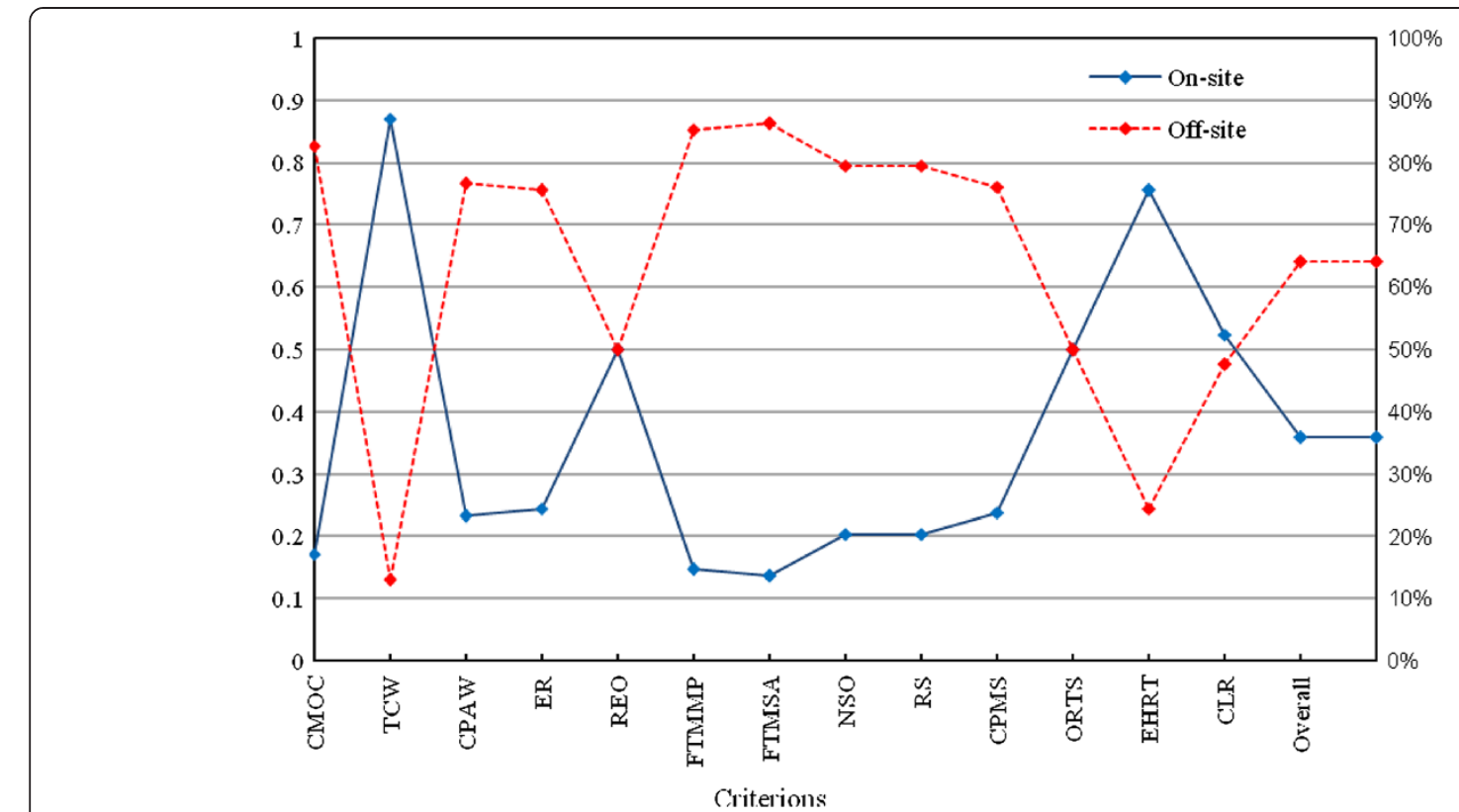

Figure 2 Comparing on-site with off-site treatment of medical waste in selected criteria and overall by Analytical Hierarchy Process (with inconsistency ratio of $0.01<0.1$ ).

although a higher weight was observed in the side of onsite treatment of medical waste, but the difference of weight between on-site and off-site was not considerable. In addition, there were similar weights for both on-site and off-site treatment in REO and ORTS criterion variables. Finally, as presented in Figure 2, AHP synthesized the above mentioned results (with $\mathrm{ICR}=0.01<0.1$ ) and revealed that, in total, the off-site treatment of medical waste was in much higher priority than the on-site treatment $(64.1 \%$ vs. $35.9 \%)$. Therefore, in most of the criterion variables and in total, the results confirmed the off-site treatment of medical waste as a better option. About treatment technology options it should be explained, by considering the previous unsuccessful experience of onsite incineration in Iran, current medical waste management regulations in the country $[8,29]$ and the results of Analytical Hierarchy Process in this study (which was not presented in detail in this manuscript), the preferred treatment option was autoclave or hydroclave. In comparison with other researches, the results of this study was in agreement with finding of Karagiannidis et al. 2010 in Greece and also Oakan 2013 in Turkey which concluded respectively, a centralized (off-site) autoclave or hydroclave and the off-site sterilization technique as best option for medical waste treatment $[27,28]$. In the meanwhile Yerabandi et al. 1998 in Canada according to the Criterion Function approach and Analytical Hierarchy Process methods (AHP) has been judged the offsite treatment location and incineration to be the best site and best alternative treatment technology for processing infectious waste respectively [17]. Nevertheless Chen et al. 2013 reported, by the end of 2012, in different cities of China 272 modern, high-standard, centralized medical waste disposal facilities installed. Among those facilities about 50\% are non-incineration treatment facilities, including the technologies of high temperature steam, chemical disinfection and microwave. In that study Chen et al. concluded each of the non-incineration technologies has its advantages and disadvantages, and none of those technology is not the best alone, due to the complexity of medical waste treatment and disposal [26].

\section{Conclusion}

Practical condition assessment indicated that most of onsite medical waste treating systems had operation and maintenance problems. In additions, other problems like difficulties in preparing spare parts, insufficient financial rescores, could be considered. Analytical Hierarchy Process (AHP) technique demonstrated that off-site treatment of medical waste was in much higher priority than the on-site one. Therefore, based on the result of AHP technique, the current problems and unsuccessful experience with on-site treating facilities, off-site central treatment can be considered as an alternative. It was predicted that the advantages of off-site central systems would be more than their disadvantages. The benefits such as the following ones can be also expected: practicability of accepting and treating medical waste of minor medical producers in the city; feasibility of receiving and treating medical waste of the surrounding cities and villages; more cost-effectiveness for larger units by reducing capital, maintenance and operating costs; more economical 
preparation of spare capacity, easy performance of future expansion and modification; feasibility of employing private sector capacity in installing and operation of medical waste testing facilities; ensuring more efficient operation of central off-site facilities in comparison with several plants (hospitals' on-site systems) in which skilled workers may not be readily available. Nevertheless in the planning of off-site central treatment facilities, disadvantages such as risks of waste consignment to public health and the environment or illegal recycling should be considered and minimized by strict monitoring and regulation.

An amendment could be made in Iran's current hazardous waste regulations to have infectious-hazardous waste sent to the central off-site for treatment. To begin with, this plan should be tested and official approval should be received; then, a central off-site can be put into practice as a pilot. Next, if it was practically successful, it could be expanded to other provinces and cities. The investment for off-site facilities can be carried out by privet sector or government. Each producer of medical waste should pay their own waste collection, treatment and disposal costs monthly. Meanwhile, the Health Ministry and the Environmental Protection Agency should strictly supervise medical waste collection, treating, and disposal.

\section{Competing interests}

The authors declare that they have no competing interests.

\section{Authors' contributions}

The overall implementations of this study were the results of efforts by corresponding author. All authors have made contribution into the review and finalization of this manuscript. All authors read and approved the final manuscript.

\section{Author details}

${ }^{1}$ Department of Environmental Health Engineering, Tabriz University of Medical Sciences, Tabriz, Iran. ${ }^{2}$ Student Research Committee, Department of Environmental Health Engineering, Tabriz University of Medical Sciences, Tabriz, Iran. ${ }^{3}$ Medical Education Research Center, Department of Statistics and Epidemiology, Tabriz University of Medical Sciences, Tabriz, Iran.

Received: 25 August 2013 Accepted: 12 April 2014

Published: 16 April 2014

\section{References}

1. Marinkovi N, Vitale K, Holcer NJ, Dzakula A, Pavic T: Management of hazardous medical waste in Croatia. Waste Manag 2008, 28(6):1049-1056.

2. Pruss A, Giroult E, Rushbrook P: Safe Management of Waste From Health-Care Activities. Geneva: World Health Organization; 1999.

3. Patwary MA, OHare WT, Sarker MH: Assessment of occupational and environmental safety associated with medical waste disposal in developing countries: A qualitative approach. Saf Sci 2011, 49:1200-1207.

4. Insa E, Zamorano M, Lopez R: Critical review of medical waste legislation in Spain. Resour Conserv Recycling 2010, 54(12):1048-1059.

5. Komilis D, Fouki A, Papadopoulos D: Hazardous medical waste generation rates of different categories of health-care facilities. Waste Manag 2012, 32(7):1434-1441.

6. Abd El-Salam MM: Hospital waste management in El-Beheira Governorate, Egypt. J Environ Manage 2010, 91:618-629.

7. Shinee E, Gombojav E, Nishimura A, Hamajima N, Ito K: Healthcare waste management in the capital city of Mongolia. Waste Manag 2008, 28(2):435-441.
8. Taghipour $\mathrm{H}$, Mosaferi M: The challenge of medical waste management: A case study in the northwest of Iran-Tabriz. Waste Manage Res 2009, 27:328-335.

9. Soliman SM, Ibrahim Ahmed Al: Overview of biomedical waste management in selected Governorates in Egypt: A pilot study. Waste Manag 2007, 27(12):1920-1923.

10. Taghipour H: Hospital and Health-Care Waste Management. Tabriz: Tabriz Medical Sciences University; 2009.

11. Askarian M, Vakili M, Kabri G: Results of a hospital waste survey in private hospitals in Fars province, Iran. Waste Manag 2004, 24(4):347-352.

12. Bazrafshan E, Mostafapoor FK: Survey of medical waste characterization and management in Iran: a case study of Sistan and Baluchestan Province. Waste Manag Res 2011, 29(4):442-450.

13. Lee BK EM, Moure-Ersaso R: Alternatives for treatment and disposal cost reduction of regulated medical wastes. Waste Manag 2004, 24(2):143-151.

14. Bdour A, Altrabsheh B, Hadadin N, Al-Shareif M: Assessment of medical wastes management practice: A case study of the northern part of Jordan. Waste Manag 2007, 27(6):746-759.

15. Qdais HA RA, Abdulla F: Characteristics of the medical waste generated at the Jordanian hospitals. Clean Techn Environ Policy 2007, 9:147-152.

16. Chaerul M, Tnaka M: A system dynamics approach for hospital waste management. Waste Manag 2008, 28(2):442-449.

17. Yerabandi S: A Criterion Function Approach to the Evaluation of Alternatives for Treatment of Infectious Hospital Waste in Environmental Engineering. Ontario: Windsor; 1998

18. Alagoz AZ, Kocasoy G: Determination of the best appropriate management methods for the health-care wastes in $\ddot{A}^{\circ}$ stanbul. Waste Manag 2008, 28(7):1227-1235.

19. Taghipour H, Mosaferi M: Characterization of medical waste from hospitals in Tabriz, Iran. Sci Total Environ 2009, 407:1527-1535.

20. Nessa K, Quaiyum MA, Khuda BE: Waste Management in Healthcare Facilities: A Review. Mohakhali, Dhaka 1212, Bangladesh, ICDDR Dhaka: Centre for Health and Population Research; 2001.

21. Patil G, Pokhrel K: Biomedical solid waste management in an Indian hospital: a case study. Waste Manag 2005, 25:592-599.

22. Diaz LF, Eggerth LL, Enkhtsetseg S, Savage GM: Characteristics of healthcare wastes. Waste Manag 2008, 28(7):1219-1226.

23. Hossain MS, Santhanam A, Nik Norulaini NA, Omar AKM: Clinical solid waste management practices and its impact on human health and environment â€" A review. Waste Manag 2011, 31(4):754-766.

24. Karamouz M, Banafsheh Zahraie B, Kerachian R, Jaafarzadeh N, Najmeh Mahjour N: Developing a master plan for hospital solid waste management: A case study. Waste Manag 2007, 27(5):626-638

25. Da Silva CE, Hoppe AE, Ravanello MM, Mello N: Medical wastes management in the south of Brazil. Waste Manag 2005, 25(6):600-605.

26. Chen Y, Ding Q, Yang X, Peng Z, Xu D, Feng Q: Application countermeasures of non-incineration technologies for medical waste treatment in China. Waste Manag Res 2013, 31(12):1237-1244.

27. Ozkan A: Evaluation of healthcare waste treatment/disposal alternatives by using multi-criteria decision-making techniques. Waste Manag Res 2013, 31(2):141-149.

28. Karagiannidis A, Papageorgiou A, Perkoulidis G, Sanida G, Samaras P: A multi-criteria assessment of scenarios on thermal processing of infectious hospital wastes: A case study for Central Macedonia. Waste Manag 2010, 30(2):251-262.

29. parliament, C.f.i.i.a.e.o.I: Medical waste management regulation of Iran. 2008. [cited 02.12.2012]; Available from: http://pasmand.tehran.ir/Default. aspx?tabid=138.

\section{doi:10.1186/2052-336X-12-68}

Cite this article as: Taghipour et al:: On-site or off-site treatment of medical waste: a challenge. Journal of Environmental Health Science \& Engineering 2014 12:68 